\title{
Web-HIPRE: multiattribute decision support system as a useful tool for water resources management
}

\author{
J. Skrzypski \& M. Imbierowicz \\ Faculty of Process and Environmental Engineering, \\ Technical University of Lodz, Poland
}

\begin{abstract}
The analysis of different scenarios for improving water quality of the Jeziorsko reservoir is presented. This artificial reservoir plays various functions, for example it is an important element of the flood control system in Poland; water from the reservoir is used for industrial and agricultural purposes, etc. This means that the control and management of water resources in this area are very complex. Web-HIPRE (HIerarchical PREference analysis on the World Wide Web) is a multiattribute decision support system which provides a set of analytical methods (e.g. analytic hierarchy process, multiattribute value theory, etc.), to support decision makers in the evaluation of different alternatives. The system described in this paper was applied to evaluate the effects of different program measures, which were proposed to improve the ecological status of the Jeziorsko water body. Using the Web-HIPRE system, the "Warta River Basin Project" was analysed in order to obtain the best scenarios for achieving objectives described in the EU Water Framework Directive.

Keywords: multiattribute decision support system, Web-HIPRE, water basin management, artificial water reservoirs.
\end{abstract}

\section{Introduction}

The main goal of implementing Water Framework Directive (WFD, 2006/60/WE) is to keep and improve the quality of water resources, taking into account quantitative aspects. Accomplishment of the aims specified in WFD requires the use of appropriate instruments and new estimation criteria. The 
particularly important tools for carrying out WFD aims include the systems of multiobjective decision optimisation.

The selection of systems, instruments and assessment criteria should be adjusted to the character and scale of the problem as well as to local conditions. The problems of water management in Poland have not been solved in a satisfying way yet. Long-term negligence, relinquishment and errors or insufficient investment outlays on water management cause quantitative and qualitative problems and also a negative impact on water resources outside Poland (the Baltic Sea, the Odra river on the border with Germany). Deteriorated or poor quality of water resources and a growing water deficit and stepping in particular regions are a barrier of the sustainable development of Poland. Hence, artificial water reservoirs in Poland are a very important element of water management.

In this study an attempt was made to apply a specialist system to aid a decision-making process, to select priorities for the optimisation of water resources management in a big water reservoir in central Poland. The study was carried out within the international WATERSKETCH program "Strategies of sustainable management of basins". A superior aim of the WATERSKETCH project is to develop principles and instruments of multiattribute and sustainable management of water resources which encompass vulnerable and degraded ecosystem of the Baltic.

In the studies presented in the paper, the current water quality in Jeziorsko reservoir was identified and reasons of poor water quality in the reservoir were described. A matrix of the effect of different factors and conditions which determine physicochemical and biological state of water in the reservoir was prepared. At the second stage of the research attention was given to the analysis of conflicting functions played by Jeziorsko reservoir. A matrix of these conflicts was prepared. At the third stage optimum actions were specified to increase efficiency of water management in Jeziorsko reservoir. For this purpose a WebHIPRE multiobjective system of decision support was devised.

\section{Multiobjective systems of decision support}

In decision making and optimisation processes, methods based on mathematical formalism are used. In such a case the decision-making process is supported by tools based on mathematical models. Most often in these cases a multiobjective model of decisions is used. The model is a matrix of partial assessment $\boldsymbol{\Theta}_{\mathrm{i}, \mathrm{j}}$; $i=1, \ldots, k ; j=1, \ldots, n$ with weight vector $\left(\omega_{\mathrm{j}}, j=1, \ldots, k\right)$ and defined technique for the aggregation of partial assessments as well as the method of variant(s) selection. It is assumed at the same time that variants of the solution compose a finite set $\left\{\boldsymbol{A}_{i}\right\} i=1,2, \ldots, n$ (where $n$-number of variants) and are independent.

The multiobjective decision models in this context are useful tools to make a reasonable selection of the proposed solution variants. The multiobjective decision model should not be either the only method to evaluate a problem, because beside a survey based on the mathematical formalism, other techniques supporting the decision-making process can and should be applied. The choice of 
an optimum solution from among many variants was described and discussed in many papers on decision theory (White [1], Findeisen [2], Keeney and Raiffa [3], Winterfeld [4]). A literature survey shows that many variants of WMD are applied. They result from the assumed mathematical formalism and the way in which partial assessments are aggregated. McDonald et al. [5] present a model for the assessment of water management enterprises. The assessment is made basing on 11 criteria $\left(\boldsymbol{K}_{i}\right)$ such as e.g. supplied water quality, surface water quality, fish and wildlife, recreation, resource conservation, agriculture preservation and enhancement, etc. For each criterion a 10-point scale was assumed. This scale is used in direct estimation $\boldsymbol{\Theta}_{\mathrm{i}, \mathrm{j}}$ of a given variant $A_{\mathrm{i}}$ in reference to a given criterion $\boldsymbol{K}_{\mathrm{i}}$. The criteria are weighted, and weights $\boldsymbol{\omega}_{\mathrm{j}}$ are also expressed using a 10-point scale. The final evaluation of each variant $A_{i}$ is determined by the weighted sum:

$$
A_{i}=\sum_{j=1}^{k} \omega_{j} \Theta_{i, j}
$$

where:

$\omega_{j}-$ weight of the j-th criterion,

$\boldsymbol{\Theta}_{\mathrm{i}, \mathrm{j}}$ - partial assessment for the $\mathrm{j}$-th criterion.

Variant $A_{\mathrm{i}}$, which gets the highest estimation is the best variant.

The judgement presented by Baas and Kwakernaak [6] who assumed the formalism of fuzzy sets is uncertain. Alley et al. [7] and Znotinas and Hipel [8] used the formalism of the fuzzy sets theory in multiobjective alternative assessments of water economy and waste management.

\section{Characteristics of the object of study}

Water management studies on an artificial water reservoir Jeziorsko and its neighbourhood were conducted. The Jeziorsko reservoir is important for water management in a big part of Poland. The reservoir is located in central Poland, in the middle course of the Warta river. In Polish conditions this is a very large reservoir: the second largest as far as its surface area and the fourth largest as its capacity is concerned. At the highest damming level in usual operating conditions the water storage capacity is 162.5 million $\mathrm{m}^{3}$ and the reservoir surface area is then $39 \mathrm{~km}^{2}$. Depending on operating conditions, these parameters change in a broad range (max. capacity 224 million $\mathrm{m}^{3}$, minimum capacity 30 million $\mathrm{m}^{3}$ ). The flow rate on the Warta river in the dam axis changes significantly and is determined mainly by the water management regime. The average annual flow rate (in the years 1950-1998) is SSQ $=49.8 \mathrm{~m}^{3} / \mathrm{s}$, at the average annual runoff 1,570 million $\mathrm{m}^{3}$ (Przedwojski [9]).

Morphometric features of Jeziorsko reservoir contribute significantly to the increase of degradability induced by external factors. Jeziorsko has a strongly elongated shape. Depending on the damming level, length of the reservoir ranges from $7 \mathrm{~km}$ to $16.3 \mathrm{~km}$. As a result, the ratio of water mass volume to the coast 
line length is high. Jeziorsko reservoir is very shallow. At a maximum level of damming the average depth of the reservoir is $4.8 \mathrm{~m}$, and at a minimum damming the average depth is only $1.7 \mathrm{~m}$. Water retained in the reservoir can easily heat up.

\section{Analysis of conflicts of Jeziorsko reservoir functions}

Conflicts of functions of the Jeziorsko reservoir were analysed. Results are presented in a graphic form (Fig. 1) which shows not only that discrepancies exist but illustrates also intensity of the conflicts (in a 4-degree scale). This intensity was determined qualitatively (subjectively), since functioning of the monitoring system makes a quantitative assessment impossible.

\begin{tabular}{|c|c|c|c|c|c|c|c|c|c|c|}
\hline 1 & Agriculture water supply & 1 & & & & & & & \multicolumn{2}{|c|}{ Conflict } \\
\hline & & & & & & & & & \multicolumn{2}{|c|}{ None } \\
\hline 2 & Flood protection & $\angle$ & 2 & & & & & $\triangle$ & \multicolumn{2}{|c|}{ Low } \\
\hline & & & & & & & & $\triangle$ & \multicolumn{2}{|c|}{ Medium } \\
\hline 3 & Industry - water supply & & & 3 & & & & $\triangle$ & \multicolumn{2}{|c|}{ High } \\
\hline 4 & Potable water supply & & & & 4 & & & $\triangle$ & \multicolumn{2}{|c|}{ Very high } \\
\hline 5 & Nature protection & 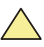 & & $\triangle$ & $\triangle$ & 5 & & & & \\
\hline 6 & Electricity production & & & & & $\angle$ & 6 & & & \\
\hline 7 & Fishing & & & & & & $\triangle$ & & & \\
\hline 8 & Recreation/Settlement & 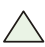 & 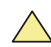 & & & $\Lambda$ & & & & 8 \\
\hline
\end{tabular}

Figure 1: Matrix of conflicting functions of Jeziorsko reservoir.

Majority of the most serious conflicts in Jeziorsko are generated by nature conservation, i.e. habitats of birds, mainly of water and wetland fowl. Since 1998 there has been a nature reserve of surface area exceeding 2350 ha. This function was not planned originally because it seriously confuses the main function of the reservoir, i.e. flood retention. Bird habitats impose also restrictions on other functions of the reservoir, including fishing and electric energy production. Bird habitats influence not only water quality in the reservoir, and in particular its sanitary state, but also intensified eutrophication of the reservoir. Recently, developing tourism has become a source of new conflicts.

\section{Analysis of impacts affecting the ecological status}

The ecological status of water in Jeziorsko reservoir is unsatisfactory. An analysis of causes should be made in view of factors responsible for water quality deterioration, which will enable development of an environmental protection program adequate to quality standards and local conditions.

Results of this analysis are shown in the graphic form (Fig. 2) as a matrix of impacts prepared according to the requirements of Water Framework Directive. 
Causal relations were indicated and intensity of the impacts was determined using a 3-degree scale: weak, medium and strong impacts.

The impacts of point sources of pollution such as municipal sewage treatment plants, legal and illegal dumping sites, contribute to degradation of the ecological status of Jeziorsko reservoir which is revealed by a deterioration of Coli titre and increased concentrations of hazardous substances (Fig. 2). A mild deterioration of quality parameters is characteristic of aerobic conditions, biogenes, phytoplankton and invertebrates. The unsatisfactory ecological status is among the others a result of the fact that water-pipe network on the tested area is 30 times longer than the sewerage network, so only $10 \%$ of sewage generated on that area is subjected to treatment.

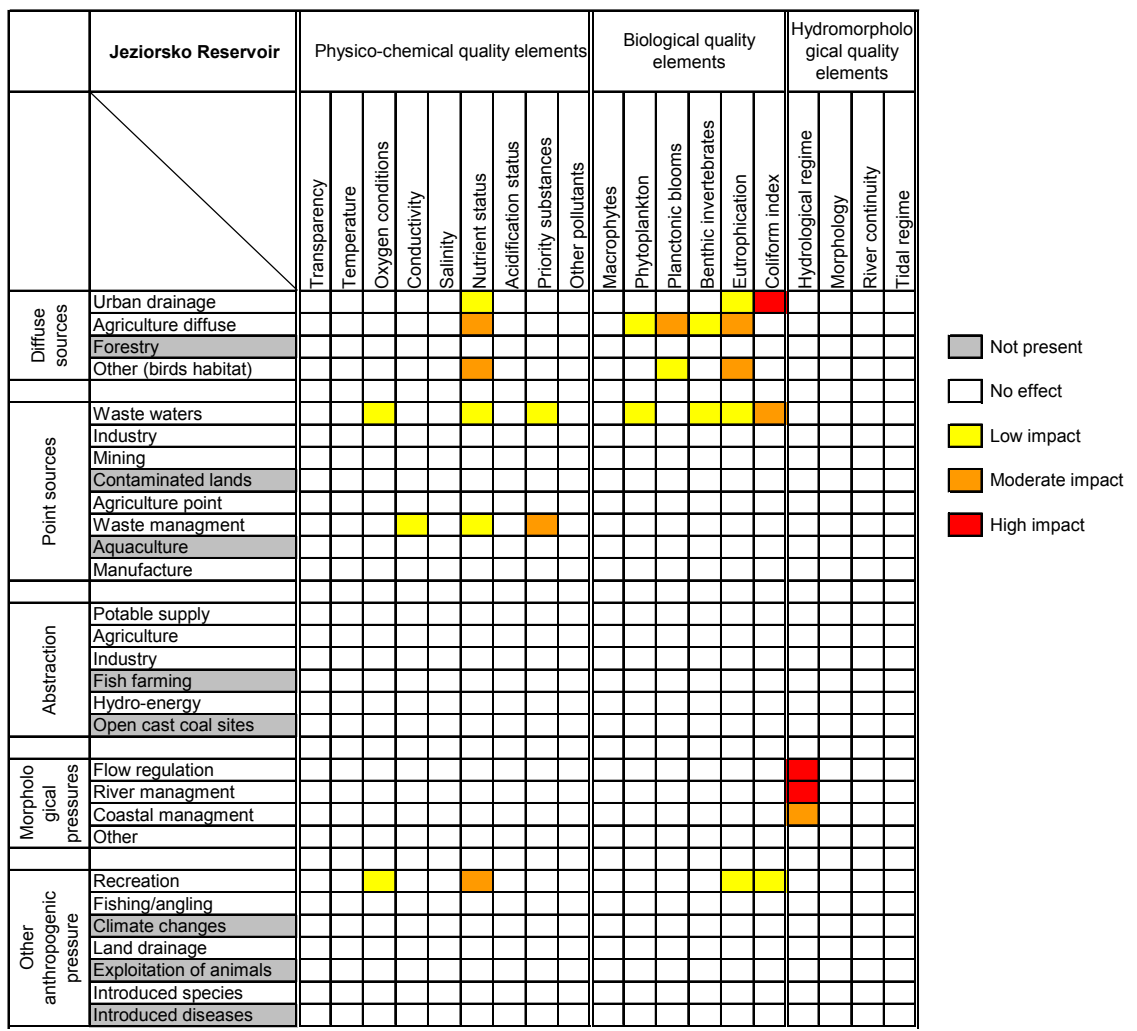

Figure 2: Matrix of impacts affecting the ecological status of Jeziorsko reservoir.

\section{Analysis of alternative scenarios of water quality improvement in Jeziorsko reservoir}

Multiattribute decision support system Web-HIPRE was developed in the Systems Analysis Laboratory (Helsinki University of Technology, Finland) on the basis of HIPRE 3+ decision support software (Hämäläinen and Lauri [10]). 
Some decision analytical methods are included in this system; Web-HIPRE supports for instance, multiattribute value theory (MAVT) (Keeney and Raiffa [3]) and the analytic hierarchy process (AHP) (Saaty $[11,12]$ ). The decision making problems are structured in the form of a value tree, whose structure consists of a goal to be achieved, attributes affecting the decision and alternatives to be chosen. The attributes are weighted according to their importance, and the alternatives are evaluated in respect to each attribute.

Web-HIPRE also supports group processes, so the individual priorities can be aggregated to composite group priorities (Keeney and Raiffa [3]). Then, the individual decision makers are considered as the highest level criteria for the alternatives. Because of Internet, which is a suitable communication channel, Web-HIPRE can be open to everyone, by using the appropriate programming language.

\subsection{Structuring of the problem}

Before the analysis and estimation of particular improvement programs which aim at the improvement of ecological status of Jeziorsko reservoir, the aim of this analysis was defined as "to achieve good ecological status of Jeziorsko reservoir by improving the critical quality elements". Within the analysis, basing on available data and impact matrix (Fig. 2), the factors which significantly deteriorate water quality in the reservoir were listed. The list includes the following factors:

- wastewaters and urban drainage (code of pressures: WASTEWATERS)

- agriculture diffuse (code of pressures: SURFACE FLOW)

- waste management (code of pressures: WASTES)

- recreation (code of pressures: TOURISTS)

- birds habitat (code of pressures: BIRDS)

Next, using data contained in the study "The Warta Program" a number of programmes which reduce the ecological impact of these factors on Jeziorsko reservoir were defined (Skrzypski et al. [13]):

- Development of sewer system and application of other sewage collecting systems, construction of new wastewater treatment plants and improvement of the existing plants by adding biogenic elements removal stages (code of programme: SEWAGE SYSTEM),

- Implementation of the programme for increasing forest area around the reservoir, change of the functions of croplands and reduction of fertiliser loads, development of ecological agriculture (programme code: FORESTING)

- Improvement of waste management system (programme code: WASTE MANAGEMENT)

- Development of tourist and recreation centre, which meets severe ecological conditions (code of programme: ECOLOGICAL RECREATION),

- Development of bird habitat management program (programme code: RESERVE MANAGEMENT). 
The next stage of the analysis was to define causal relations between particular elements of the considered problem. The Web-HIPRE model is builtup by defining the relationship (links) between each of the elements. Structure of these relations is shown in Fig. 3.

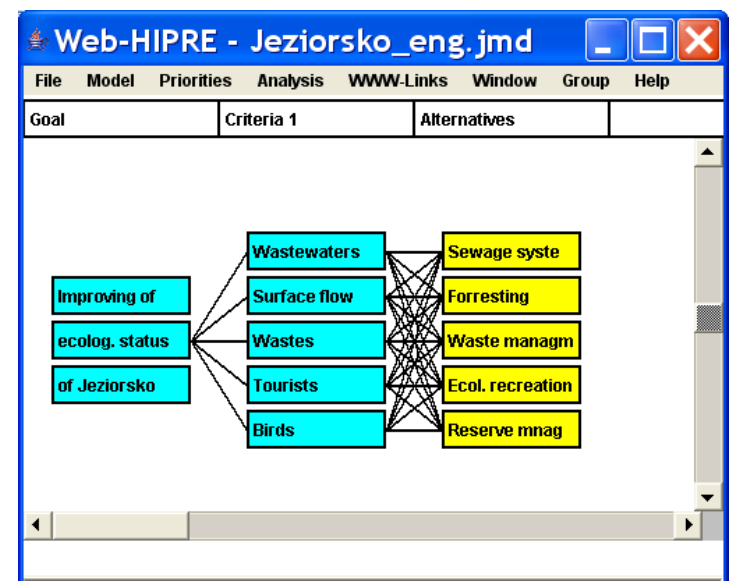

Figure 3: $\quad$ Structure of the diagram defining causal relations between elements of the decision system.

\begin{tabular}{|c|c|c|c|c|}
\hline \multicolumn{5}{|l|}{ Ratings } \\
\hline & Wastewaters & Surface flow & Wastes & Tourists \\
\hline Min Rating & 0.0 & 0.0 & 0.0 & 0.0 \\
\hline Sewage syste & 75.0 & 0.0 & 0.0 & 25.0 \\
\hline Forresting & 0.0 & 30.0 & 5.0 & 10.0 \\
\hline Waste manag & 0.0 & 15.0 & 60.0 & 15.0 \\
\hline \begin{tabular}{|l|} 
Ecol. recreati \\
\end{tabular} & 5.0 & 5.0 & 10.0 & 20.0 \\
\hline \begin{tabular}{|l|} 
Reserve mna \\
\end{tabular} & 0.0 & 15.0 & 0.0 & 0.0 \\
\hline Max Rating & 100.0 & 100.0 & 100.0 & 100.0 \\
\hline \multirow[t]{2}{*}{ Unit } & $\%$ & $\%$ & $\%$ & $\%$ \\
\hline & 11 & & & \\
\hline Clear Ratings & & оK & Cancel & Import... \\
\hline
\end{tabular}

Figure 4: Assessment of the effect of improvement programs on the reduction of undesirable impacts on water quality in Jeziorsko reservoir.

\subsection{Assessment of significance of the improvement programs}

At a subsequent stage of the analysis significance of particular improvement programs for reduction of undesirable impacts was estimated. The results of implementation of the program measures, which intentionally can improve the ecological status of Jeziorsko reservoir, expressed as percentage of the reduction of every impact are as follows: 
Table presented in Fig. 4 which illustrates assessment of the efficiency of implementation of particular improvement programs, allows us to determine significance of these programs for water quality improvement in the reservoir. Due to proper algorithms, the programs are transformed into a normalised form, i.e. in the vector of values $K_{\mathrm{i}} \in\{0 \ldots 1\}$. The transformation takes place using linear functions, but it should be stressed that the Web-HIPRE system admits also normalisation of functions according to non-linear transforms (e.g. hyperbolic).

\subsection{Determination of impact weights on water status in the reservoir}

To accomplish the analysis it was necessary to determine the weight vector which described the effect of particular factors, deteriorating water quality in the reservoir, on its ecological status. Results of the estimation are given in Fig. 5.

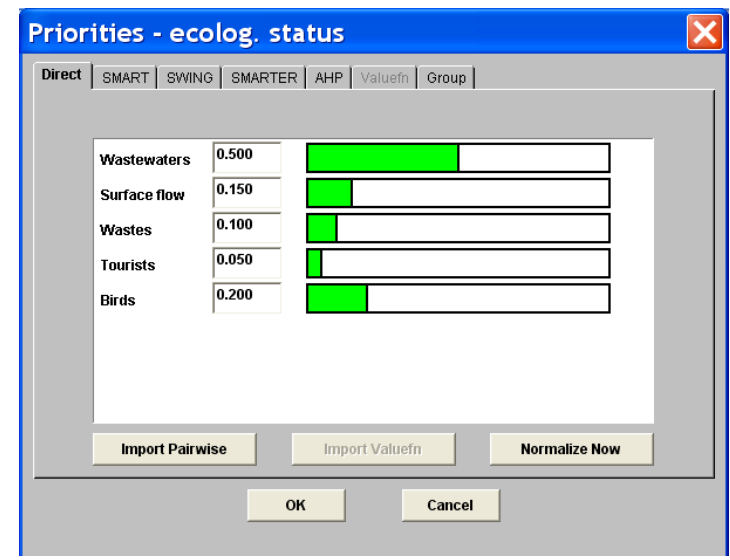

Figure 5: The weights of main impacts on the ecological status of Jeziorsko reservoir.

After introducing the data to the Web-HIPRE system the program makes a calculation cycle, and as a result of the analysis the measures' efficiencies which improve the ecological status of the water body are obtained. The resulting efficiencies are expressed on an abstract scale. The result gives an idea of the measures' relative efficiencies rather than their absolute efficiencies.

\subsection{Final results of program assessment}

A result of the analysis is shown in the form of a diagram illustrating efficiency of particular improvement programs. Figure 6 shows an example of such a solution.

From data shown in Fig. 6 it follows that the highest efficiency has the improvement program entitled SEWAGE SYSTEM. It means that development of sewer systems on the Jeziorsko reservoir area and application of other sewage 
collecting systems, as well as a construction of new wastewater treatment plants and improvement of the existing plants by adding biogenic elements removal stages, are the best options for achieving good ecological status of Jeziorsko reservoir water body. Other measures of the programs, e.g. increasing forest area around the reservoir, changing of the functions of croplands and reduction of fertilisers loads, development of ecological agriculture, improvement of waste management system, development of ecological recreation and bird habitat management program are not so effective as the first option.

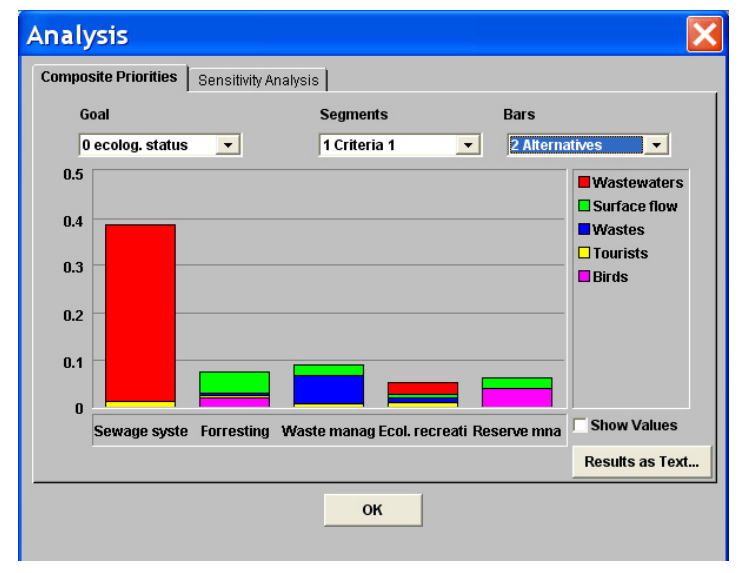

Figure 6: The results of Web-HIPRE analysis.

\section{Summary}

Possibilities of an optimum management of water resources and ecological status of these resources depend on many different factors and natural as well as anthropogenic conditions. Accomplishment of various projects concerning water management requires the application of multiobjective systems. Selection of the applied system and detailed criteria depends on local conditions and available information.

Application of the WEB-Hipre system in the optimisation of actions referring to water management in Jeziorsko reservoir is presented. Results obtained lead to a conclusion that at present the most advantageous method to improve the ecological status of Jeziorsko reservoir is to develop water supply and sewage removal systems in the reservoir region, which consists in building new sewage treatment plants, modernisation of the existing and implementation of other efficient solutions for water and sewage management in the region.

\section{Acknowledgement}

The work upon which this paper is based was supported by the funds provided by the INTERREG IIIB project Watersketch. 


\section{References}

[1] White, D., Decision Methodology, J. Wiley \& Sons Inc: Chichester, England, 1975.

[2] Findeisen, W., System Analysis - Fundamentals and Methodology (Analiza systemowa - Podstawy i metodologia), PWN: Warszawa, 1985 (in Polish).

[3] Keeney, R.L., Raiffa, H., Decisions with Multiple Objectives: Preferences and Value Tradeoffs, John Wiley \& Sons, Inc.: New York, 1976.

[4] Winterfeldt von D., A decision aiding system for improving the environmental standard setting process. In: Cichocki M., Straszak A. (eds) System Analysis application to complex programme, Pergamon Press: Oxford, 1978.

[5] MacDonald, D.V., Barney, K.P., Jones, S.F., Procedure for Evaluation of Engineering Alternatives, Water Resources Bulletin 13 (3), pp. 583-598, 1977.

[6] Baas, S.M., Kwakernaak, H., Rating and Ranking of Multiple-Aspects Alternatives Using Fuzzy Sets, Automatika, 13, pp. 47-58, 1977.

[7] Alley, H., Bacinello, C.P., Hipel, K.W., Fuzzy Set Approaches to Planning in the Grand River Basin, Advances in Water Resources 2, pp. 312, 1979.

[8] Znotinas, N.M., Hipel, K.W., Comparison of Alternatives Engineering Design, Water Resources Bulletin, 15,(2), pp. 354-368, 1979.

[9] Przedwojski, B. (eds). Exploitation and Impact of Big Plain Water Reservoirs on the Case of Jeziorsko Reservoir (Eksploatacja $i$ oddziaływanie dużych zbiorników nizinnych na przykładzie zbiornika wodnego Jeziorsko) Wydawnictwo Akademii Rolniczej w Poznaniu: Poznań, Poland, 1999 (in Polish).

[10] Hämäläinen, R.P., Lauri, H., HIPRE 3+ User's Guide, Systems Analysis Laboratory, Helsinki University of Technology: Helsinki, Finland, 1995.

[11] Saaty, T.L., Highlights and critical points in the theory and application of the Analytic Hierarchy Process, European Journal of Operational Research, 74, pp. 426-447, 1994.

[12] Saaty, T.L., The Analytic Hierarchy Process, McGraw-Hill, Inc.: New York, 1980.

[13] Skrzypski, J. et al., Environmental Protection Programme for Lodz Voivodship (Program ochrony środowiska dla województwa łódzkiego), Marshal`s Office of the Lodz Voivodship: Łódź, Poland, 2003 (in Polish). 